\title{
Climate and interrelated tree regeneration drivers in mixed temperate-boreal forests
}

\author{
Nicholas A. Fisichelli • Lee E. Frelich • \\ Peter B. Reich
}

Received: 13 August 2012/Accepted: 15 November 2012/Published online: 28 November 2012

(C) The Author(s) 2012. This article is published with open access at Springerlink.com

\begin{abstract}
Forest compositional shifts in response to climate change are likely to be initially detectable in the understory tree regeneration layer near species range limits. Because many factors in addition to climate, such as seedbed and soil characteristics, overstory composition, and interactions with other understory biota, drive tree regeneration trends, a thorough understanding of the relative importance of all variables as well as their interrelationships is needed. The range limits of several widespread temperate and boreal tree species overlap in the upper Great Lakes region, USA, thus facilitating an observational study over relatively short regional climate gradients. We used redundancy analysis and variation partitioning to quantify the unique, shared, and
\end{abstract}

Electronic supplementary material The online version of this article (doi:10.1007/s10980-012-9827-z) contains supplementary material, which is available to authorized users.

N. A. Fisichelli · L. E. Frelich · P. B. Reich

Department of Forest Resources, University of Minnesota, 1530 Cleveland Avenue North, St. Paul, MN 55108, USA

Present Address:

N. A. Fisichelli ( $\square)$

Department of Silviculture and Forest Ecology of the

Temperate Zone, Georg-August-Universität Göttingen,

Büsgenweg 1, 37077 Göttingen, Germany

e-mail: nfisichelli@gmail.com

P. B. Reich

Hawksbury Institute for the Environment, University of

Western Sydney, Penrith, NSW 2753, Australia total explanatory power of four sets of explanatory variables. The results showed that all four variable sets (climate $9.5 \%$, understory environment $13.7 \%$, overstory composition $26.3 \%$, and understory biota $13.8 \%$ ) were significantly associated with tree regeneration compositional variation in mixed temperate-boreal forests. Partitioning also revealed high confounded or shared explanatory power, but also that each set contributed significant unique explanatory power not shared with other sets. Spatial patterning in regeneration composition was strongly related to broad scale environmental patterns, while the large majority of unexplained variation did not have a detectable spatial structure, suggesting factors with local scale variability. Future forest shifts across the landscape will depend not only on the rate and direction of climate change but also on how the strengths and interrelationships among other explanatory variables, such as overstory composition and understory biota, shift with a changing climate.

Keywords Ecotone - Overstory neighborhood effects - Mixed temperate-boreal forest - Tree regeneration - Variation partitioning

\section{Introduction}

Tree regeneration layer composition is driven by numerous interrelated and covarying biotic and abiotic 
variables (Grubb 1977; Arii and Lechowicz 2002; McEwan et al. 2011). These variables can be grouped into logical driver sets, such as climate, overstory composition, understory environment, and understory biota, which due to their interrelationships have varying degrees of overlapping influence on tree regeneration.

For example, climate directly impacts germination, growth, and survival and indirectly affects tree regeneration through its relationships with the other explanatory variables (Barnes et al. 1998). The composition of the overstory, which is itself partially the result of responses to climate, directly influences propagule availability and strongly affects understory processes and properties including nutrient availability, seedbed conditions, and amount and timing of shading (Frelich et al. 1993; Finzi et al. 1998). The understory environment, including seedbed type, soil texture and $\mathrm{pH}$, and light availability, drives not only tree regeneration but also the composition of competing vegetation layers (Canham et al. 1996; Walters and Reich 1996), while the range of environmental conditions, such as soil texture, over which a forest type occurs, is itself partially determined by climate (Henne et al. 2007). Understory biota, including competing vegetation layers and selective herbivores, act as filters that determine which tree species are able to successfully compete and survive in the regeneration layer (Côté et al. 2004; Royo and Carson 2006) and are themselves simultaneously responding to the same conditions as the regeneration layer.

Each driver set can thus be characterized as having both unique influences on tree regeneration that cannot be attributed to other factors and shared explanatory power due to confounded relationships. Too much emphasis can be placed on single factors when in reality other covarying factors may at least be partially driving trends (Legendre and Legendre 1998). Factors influencing regeneration, due to their filtering effects at early stages of development, can have long-term impacts on forest composition and understanding the unique and shared explanatory power of these variables is critical to estimating compositional shifts within forest types forecast to be sensitive to climate change (Prentice et al. 1991; Frelich and Reich 2010).

The upper Great Lakes region in North America contains a broad forest transition zone where temperate and boreal tree species reach their northern and southern limits, respectively (Pastor and
Mladenoff 1992; Goldblum and Rigg 2010). Because mixed temperate-boreal forests within this zone include species at or near their temperature and moisture driven range limits, small changes in climate are forecast to have major effects on composition, with tree species shifting their range limits north and east (Iverson and Prasad 1998; Scheller and Mladenoff 2005; Frelich and Reich 2010). Recent field studies have confirmed this climate sensitivity and indicate that temperate species are expanding across local ecotonal boundaries into boreal forest (Fisichelli 2012) and that temperate and boreal saplings exhibit rank reversals in growth rates across their overlapping range limits (Fisichelli et al. 2012). However, due to the complex role of climate within ecosystems, determining the total and relative influences of climate on tree regeneration across the region has been difficult to ascertain. Furthermore, much research on forest dynamics and underlying drivers has focused on 'pure' or 'homogeneous' temperate or boreal stands (Forcier 1975; Frelich and Reich 1995; Kneeshaw and Bergeron 1996), while fewer studies have specifically targeted mixed stands (Buell and Martin 1961; Diochon et al. 2003; Kneeshaw and Prevost 2007). Quantifying the interrelated roles of explanatory variables across mixed stands is needed in order to better understand which factors are determining composition, especially in light of global change concerns (Millar et al. 2007; Frelich and Reich 2009).

The objective of this study was to examine and quantify the explanatory relationships among tree regeneration variables within mixed temperate-boreal forests across the landscape. By simultaneously studying four driver sets: climate, understory environment, overstory composition, and understory biota, we can quantify the unique, shared, and total variation in understory composition explained by each set. We specifically sampled sites across the northern, southern, and western limits of mixed stands in the Great Lakes region of North America to test the hypothesis that tree regeneration composition is sensitive to temperature and precipitation, to assess the degree of overlap in explanatory power among driver sets, to examine the individual variables that are covarying, and finally to quantify the spatial scales at which we were able to explain tree regeneration compositional variation in mixed temperate-boreal stands. 


\section{Methods}

Study sites and field sampling

Mixed temperate-boreal forest stands were sampled at 124 sites over a three year period (2008-2010) across a $170,000 \mathrm{~km}^{2}$ area in northern Minnesota, WI, and the Upper Peninsula of Michigan, USA (Fig. 1a). The dominant natural disturbance in these dry-mesic to wet-mesic forests is wind, with heavy blowdown events occurring every $300+$ years, while intense fires are less frequent with a return interval of 1,000+ years (MN DNR 2003; Schulte and Mladenoff 2005). Selection criteria for study sites included mature, upland forest with an overstory composition of both temperate and boreal tree species. Stands across this region are typically of second-growth origin, having been harvested 70-100 years ago, and are at the understory reinitiation stage (Oliver 1980).

Study plots were $314 \mathrm{~m}^{2}$ and each site had an average of 3-4 plots, depending on stand size (456 total plots). Tree stems were sampled by size class within nested plots. Overstory trees, $\geq 10 \mathrm{~cm} \mathrm{dbh}$ (diameter at breast height, measured at $1.3 \mathrm{~m}$ above the ground surface), were measured within a $10 \mathrm{~m}$ radius plot. This plot size was found to capture the local overstory neighborhood area of influence in a similar forest type (Frelich et al. 1993). Understory stems were tallied in two size classes, $<2 \mathrm{~m}$ height and $<10 \mathrm{~cm}$ dbh within a $5 \mathrm{~m}$ radius subplot centered inside the overstory plot.

Understory tree regeneration variables were a priori divided into four explanatory data sets, climate, understory environment, overstory composition, and understory biota, based on previous knowledge regarding similarities in the scale and role of individual variables (Table S1). As weather stations are not available near most study sites, climate data were extracted from PRISM interpolated climate surfaces (Daly et al. 2008). Five climate variables (1978-2007 averages) considered a priori as likely biologically influential were included as potential explanatory variables: mean annual precipitation, mean summer precipitation (June-August), mean annual temperature, mean summer temperature (June-August), and mean minimum January temperature. Because the climate data are available as monthly means, other potential climate variables were highly correlated with this set (e.g., growing degree days and summer temperature, $r=0.95)$. In general, the climate grades from dry and continental to wet and temperate from west to east across the region, however these patterns vary by season (Fig. 1b-f).

The understory environment set of eight variables described conditions in the understory and included seedbed characteristics, soil texture and $\mathrm{pH}$, and available light (Table S1). Earthworm disturbance severity was included in the understory environment set because nonnative earthworms strongly affect the seedbed environment, specifically the presence and depth of the organic and upper mineral soil horizons (Frelich et al. 2006; Eisenhauer et al. 2007), and thus provide an integrated measure of environmental conditions at the forest floor. The severity of earthworm disturbance was measured for each plot using a 4 point scale based on the presence and characteristics of the litter and organic layers, exposure of mineral soil, formation of a thick soil A horizon, density of earthworm middens, and presence of worms found during soil collection. Soil $\mathrm{pH}$ and sand and clay particle fractions were determined from samples of the upper $20 \mathrm{~cm}$ of mineral soil. Regional variation in soil $\mathrm{pH}$ and percent sand are shown in Fig. 1g, h. Leaf litter thickness and the percent cover of leaf litter and moss were measured in each understory subplot. Canopy openness at $1 \mathrm{~m}$ above ground level was determined at plot center using a spherical concave densiometer.

Overstory composition was calculated based on species basal area. The potential pool of overstory tree species included the most abundant species, here defined as present at more than $50 \%$ of sites. This resulted in six species from three functional groups: boreal broadleaf Betula papyrifera Marsh. and Populus tremuloides Michx., boreal conifer Abies balsamea (L.) Mill. and Picea glauca (Moench) Voss, and temperate broadleaf Acer rubrum L. and Acer saccharum Marsh. (Table S1). Each of these overstory species was present at more than $70 \%$ of sites and the set accounted for, on average, $80 \%$ of site basal area. The spatial patterns of A. saccharum and P. tremuloides basal area are depicted in Fig. 1i, j.

The understory biota set included six herbaceous and woody functional vegetation groups and browse pressure, which reflect competitive and trophic interactions (Table S1). Graminoid (grasses and sedges) (Fig. 1k), forb (broadleaved herbaceous species) (Fig. 11), fern, and low shrub (e.g., Vaccinium spp. L., Diervilla lonicera Mill., and Rubus spp. L.) percent 
(a) Study locations

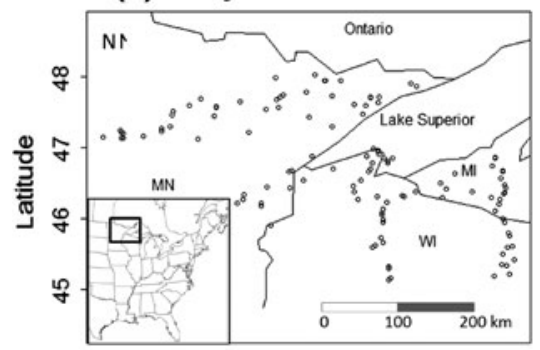

(d) Mean annual temperature

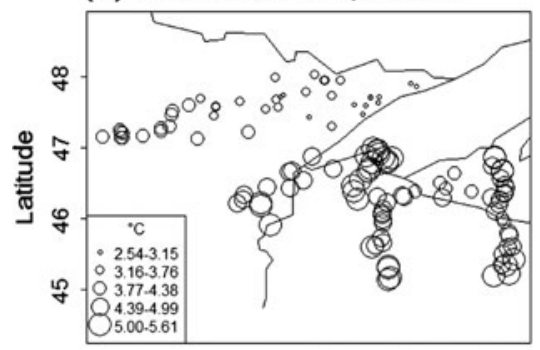

(g) Soil pH

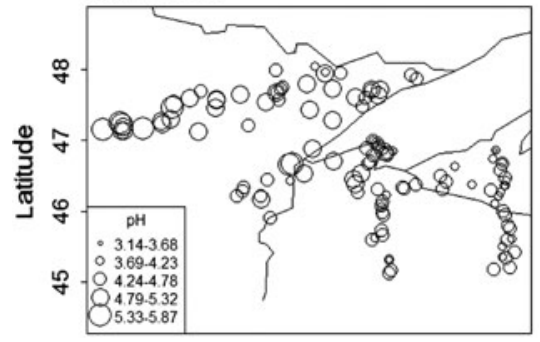

(j) Populus tremuloides basal area

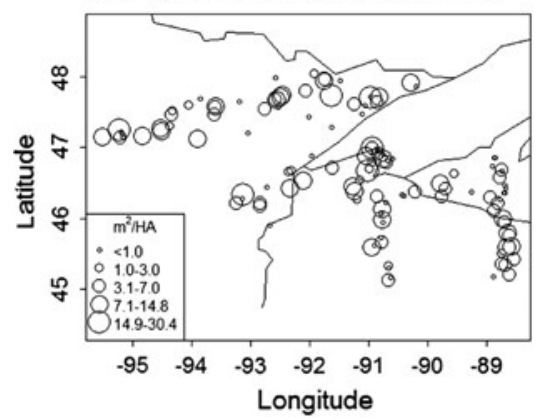

(b) Mean annual precipitation

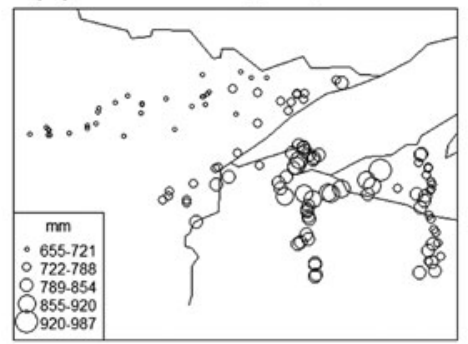

(e) Mean summer temperature (JJA)

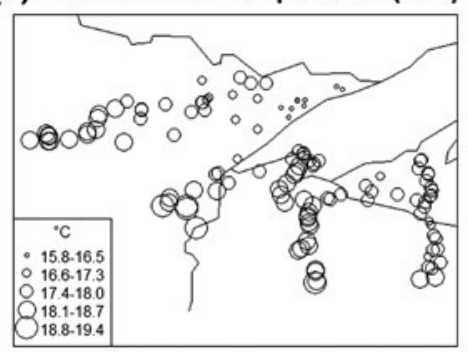

(h) Soil sand fraction

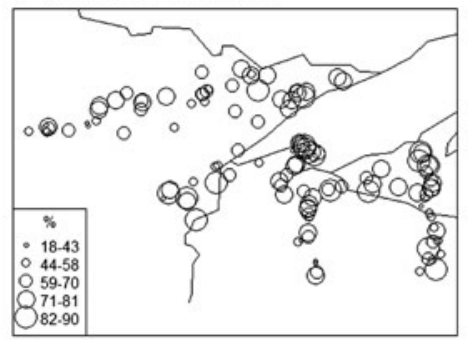

(k) Graminoid cover

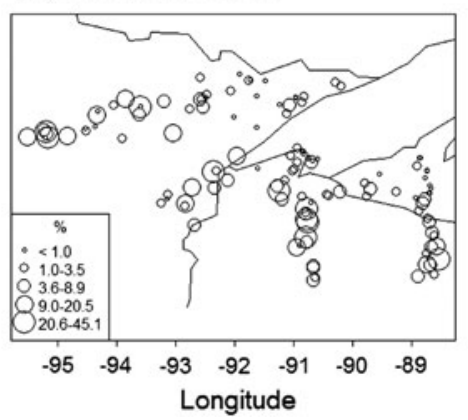

(c) Mean summer precipitation (JJA)

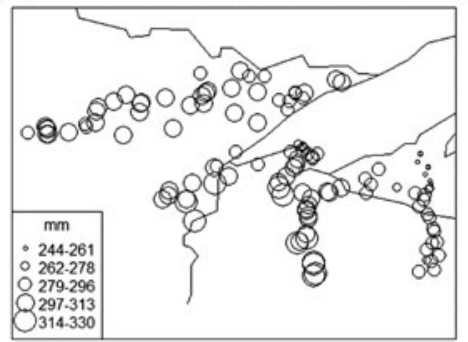

(f) Mean January minimum temperature

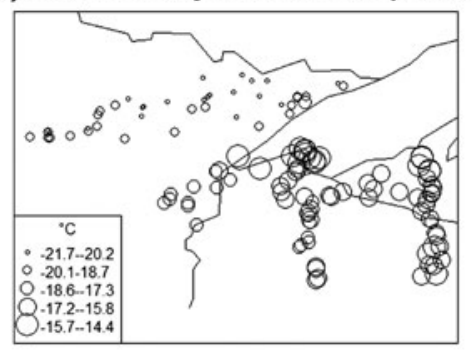

(i) Acer saccharum basal area

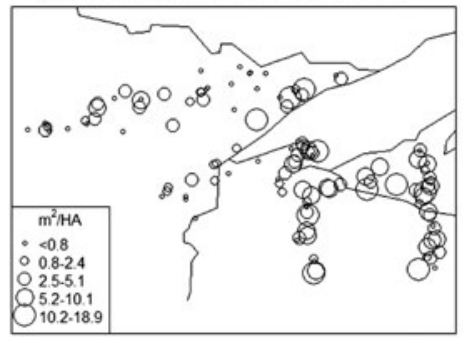

(I) Forb cover

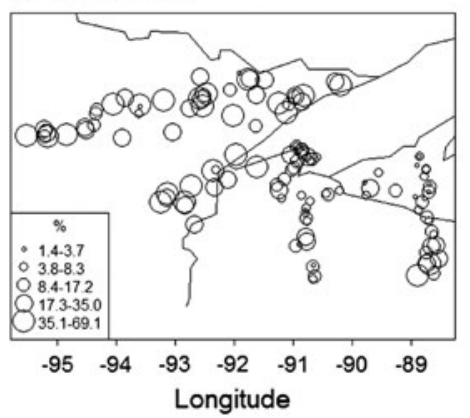

Fig. 1 Locations of study sites, upper Great Lakes region USA, and spatial patterns of selected understory regeneration drivers. a Study sites. Climate variables include b mean annual precipitation, c mean summer precipitation (JJA), d mean annual temperature, e mean summer temperature (JJA), and

cover were estimated within each understory subplot. Tall shrub (e.g., Corylus cornuta Marsh. and Acer spicatum Lam.) stem density was measured in two size classes, $<1 \mathrm{~m}$ and $\geq 1 \mathrm{~m}$ in height, within each f mean January minimum temperature. Understory environment variables are $\mathbf{g}$ soil $\mathrm{pH}$ and $\mathbf{h}$ soil sand fraction. Overstory variables include the basal area of $\mathbf{i}$ Acer saccharum and j Populus tremuloides. Understory biota include the percent cover of $\mathbf{k}$ graminoids and $\mathbf{l}$ forbs

understory subplot. Site browse pressure, primarily from white-tailed deer (Odocoileus virginianus), was assessed on a four point scale as the proportion of branches with browse damage on individual maple 
(Acer spp.) stems within the browse layer (0.25-2.0 m in height).

\section{Statistical analyses}

To explore relationships among explanatory variables and the response matrix, we used a multivariate method of variation partitioning with partial and simple redundancy analysis (RDA) (Borcard et al. 1992; Økland and Eilertsen 1994). RDA is a constrained multivariate ordination technique that is essentially the multivariate extension of multiple regression (Legendre and Legendre 1998). Plot data were averaged to the site level in order to assess trends across the region and to protect against pseudoreplication. The response variables, tree species understory stem densities were standardized using the Hellinger transformation to optimize model performance (Legendre and Gallagher 2001). Six boreal and 13 temperate species were present in $>10 \%$ of sites in the understory and were included as the response variables (Table S2).

Variation partitioning determines the unique, shared, and total explained variation contributed by each set of explanatory variables. The unique explained variation is that portion explained by a variable or a set of variables after controlling for all other measured variables. The shared variation is the confounded portion or explained variation that is common to more than one set of variables. The total variation explained by a set of variables is the sum of its unique and shared portions. Partitioning and the calculation of adjusted $R^{2}$ values are accomplished by running multiple RDAs with differing sets of explanatory variables (Borcard et al. 1992; Peres-Neto et al. 2006).

The four explanatory data sets each initially contained five to eight variables. In order to identify the individual variables within each set that were significantly associated with regeneration, we ran a stepwise selection process using two stopping criteria, model adjusted $R^{2}$ and variable retention at a permutation $P$ value of 0.05 (Blanchet et al. 2008). Additionally all retained variables within each set had to have a variance inflation factor (VIF) of $<5$. Explanatory relationships among individual variables from all sets were explored through a correlation biplot of the full RDA model used in variation partitioning.
Since we were interested in shifts in tree regeneration composition across the region, we assessed the spatial patterns within the data and how well we captured these spatial trends. We used the principal coordinates of neighbor matrices (PCNM) method to model spatial structure in tree regeneration trends detectable in the study design (Borcard and Legendre 2002). Through principal coordinate analysis of the geographic distance matrix among sites, 76 positive eigenfunctions were created. Stepwise selection, again using model adjusted $R^{2}$ and variable retention at a permutation $P$ value of 0.05 , was run to determine the significant eigenvectors that captured the spatial pattern of tree regeneration composition. We then ran a variation partitioning model using two variable sets, the combined sets of regeneration explanatory variables and the set of PCNM eigenfunctions, to examine the ability of explanatory variables to explain both spatially and non-spatially structured variation in tree regeneration. The significance of all RDA models, RDA axes, and variation partitioning components were tested via permutation procedures $(P$ value $=0.05)$. PCNM, variation partitioning, RDA models, and stepwise selection were run using the 'vegan' package (v. 1.17-6) (Oksanen et al. 2011) in R (v. 2.12) (R Development Core Team 2008).

\section{Results}

\section{Explanatory variables}

Initial stepwise selection procedures within each of the four driver sets chose a total of 19 variables associated with understory tree regeneration patterns (Table 1). Within the climate set, the final selected variables were mean summer temperature and mean annual precipitation. Additionally, six of eight environmental variables, five of six overstory species, and six of seven understory biota variables were selected. Explanatory power (adjusted $R^{2}$ ) of each individual variable based on RDA analyses is also shown in Table 1. Acer saccharum basal area, soil $\mathrm{pH}$, summer temperature, Populus tremuloides basal area, and annual precipitation were the five strongest individual explanatory variables. 
Variation partitioning

The results of variation partitioning indicate that all explanatory variable sets had both significant explanatory roles and strong interrelationships (Fig. 2, see also Fig. S1 for complete partitioning among all driver sets). The overall model including all four driver sets had an adj. $R^{2}$ of 0.42 and each set of variables had significant total and unique explanatory contributions (all $P$ values $<0.005$ ). Climate, environment, and biota each individually explained about $10-14 \%$ of regeneration variation, while overstory composition explained $26 \%$. The unique portions, which represent explained variation that can only be attributed to individual explanatory variable sets, accounted for 22-61\% of each set's explanatory power, with understory biota and overstory composition having the smallest and largest unique proportions, respectively. Conversely and as expected, there was a large amount of shared explanatory power, $39-78 \%$ of the explained variation attributed to each set.

The extent of shared explanatory relationships among all pairs of driver sets is shown in Fig. 3. Climate shared $21-45 \%$ of its explanatory power with each of the other sets. The understory environment and understory biota sets had similar levels of shared explained variation as climate (ranging from 27 to $40 \%$ for the former and from 31 to $49 \%$ for the latter). Overstory composition, which explained the greatest variation, showed the lowest rates of confounding, 8-25\%. Overall, these levels of confounding indicate complex relationships among all sets of explanatory variables.

Explanatory relationships among individual variables are depicted in a correlation biplot of the RDA model (Fig. 4). The biplot reveals the suites of associated variables that are driving tree regeneration trends within the first two RDA axes. Axes 1 and 2
Table 1 Explanatory variables selected during stepwise selection procedures for variation partitioning models
Variable selection occurred within each variable set and the order of selection is shown. Individual $R^{2}$ are based on RDA models with only the single explanatory variable included and the Hellinger transformed understory tree species stem density as the response variable

\begin{tabular}{llll}
\hline Variable & Acronym & Individual adj. $R^{2}$ & $\begin{array}{l}\text { Within group } \\
\text { selection } \\
\text { order }\end{array}$ \\
\hline Climate & & \\
Summer temperature & Temp & 0.06 & 1 \\
Annual precipitation & PPT & 0.04 & 2 \\
Environment & & & \\
Soil pH & pH & 0.07 & 1 \\
Moss & Moss & 0.02 & 2 \\
Earthworm severity & Worm & 0.02 & 3 \\
Canopy openness & Light & 0.01 & 4 \\
Leaf litter & Litter & 0.02 & 5 \\
Sand & Sand & 0.02 & 6 \\
Overstory & & & 1 \\
Acer saccharum & AcsaTr & 0.17 & 2 \\
Populus tremuloides & PotrTr & 0.06 & 3 \\
Acer rubrum & AcruTr & 0.03 & 4 \\
Betula papyrifera & BepaTr & 0.03 & 5 \\
Abies balsamea & AbbaTr & 0.02 & 1 \\
Understory biota & & & 2 \\
Forbs & Forbs & 0.05 & 3 \\
Graminoids & Grams & 0.03 & 4 \\
Browse pressure & Browse & 0.02 & 6 \\
Low shrubs & L. Shrub & 0.03 & 0.03 \\
Tall shrubs $<1$ m & T. Shrub & 0.01 & \\
Ferns & Ferns & & \\
\hline
\end{tabular}


(a) Climate

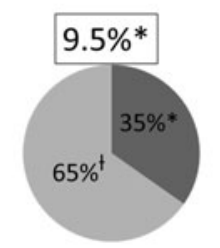

(c) Overstory

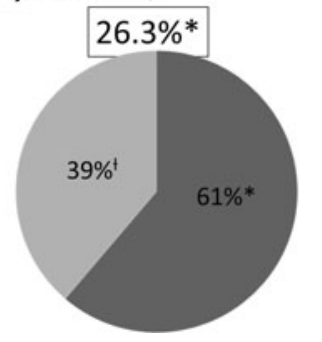

(b) Understory Environment

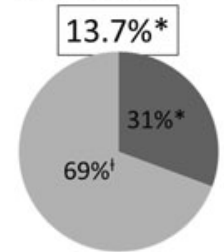

(d) Understory Biota

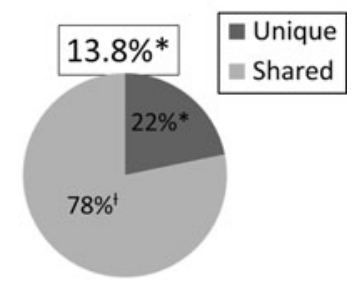

Fig. 2 Unique, shared, and total variation of the tree regeneration layer explained by a climate, $\mathbf{b}$ understory environment, c overstory composition, and $\mathbf{d}$ understory biota. Values were determined through variation partitioning among all driver sets. The full variation partitioning model with all 4 driver sets explained $42 \%$ of variation in the regeneration layer (based on adj. $R^{2}$ ). Shaded areas within and among circles are proportional to variation explained. See text for specific variables within each driver set. ${ }^{*} P<0.005$, ${ }^{\dagger}$ cannot be tested

explained 19.7 and $10.9 \%$ of total variation, respectively, and together accounted for $73 \%(30.6 / 42)$ of the explained variation. Axis 1 mainly represented variation in overstory composition and related variables. Overstory composition shifted from dominance by Populus tremuloides, Betula papyrifera, and Abies balsamea at the negative end of the axis to Acer saccharum at the positive end. Overstory P. tremuloides, B. papyrifera, and A. balsamea were positively associated with understory light levels, low shrub cover, tall shrub density, moss cover, and forb cover. Conversely, A. saccharum overstory basal area was negatively related to these variables and positively correlated with leaf litter cover and annual precipitation.

Axis 2 mainly reflected nutrient and climate gradients, with soil $\mathrm{pH}$ and summer temperature positively associated and annual precipitation and soil percent sand negatively associated with the axis. Also, Acer rubrum basal area was associated with cool, wet, acidic, and sandy conditions along the negative end of axis 2 . Additional variables with positive loadings on axis 2 were graminoids, browse pressure, and earthworm invasion severity..

Accounting for spatial patterns

As expected, the PCNM analysis found significant spatial structure in regeneration layer composition. Stepwise selection identified 15 significant PCNM eigenvectors $(1-7,9,10,12-14,24,54,60)$ (adj. $R^{2}=0.24$ ) that mainly represented broad-scale variation across the region. The sets of explanatory variables and the PCNM eigenvectors together explained $44.5 \%$ of the variation in the tree regeneration layer (Fig. 5). The explanatory variable sets explained the majority, $86.1 \%(21.0 / 24.4)$, of the total spatially structured tree regeneration variation. Roughly half (21.0/41.1) of the explained variation in regeneration composition was spatially structured and the large majority of variation unexplained by the explanatory variable sets, $94 \%(55.5 / 58.9)$ did not have a detectable spatial pattern.

\section{Discussion}

Although it is difficult to cleanly assign causative effects from an observational study, our field-based research clearly shows the multitude of factors that must be taken into account when attempting to understand and model vegetation-environment dynamics near range boundaries. The tree regeneration layer reflects a complex suite of associated variables, including climate, understory environment, overstory composition, and understory biota. Even though there were numerous interrelationships among sets of explanatory variables, each was significantly associated with a unique portion of regeneration compositional variation, underscoring the large number of factors influencing the performance of tree species in the regeneration layer. An initial goal of this study was to test whether the tree regeneration layer was responding to climate and our results reveal that even given the strengths of other explanatory variables, tree regeneration in mixed temperate-boreal stands is sensitive to temperature and precipitation gradients. The overall influence of climate may have been underestimated as only means were included in analyses. Other climatic shifts such as changes in extreme events (heat, drought, and late-spring frosts), 
(a) Climate + Environment $=19.5 \%$

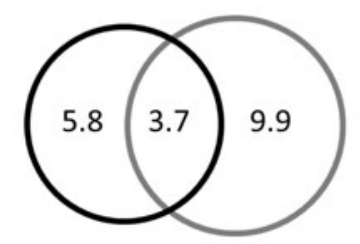

(d) Environment + Overstory $=34.5 \%$

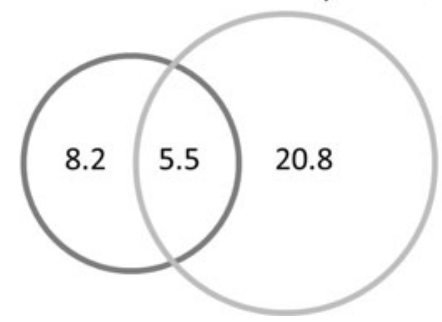

(b) Climate + Overstory $=33.9 \%$

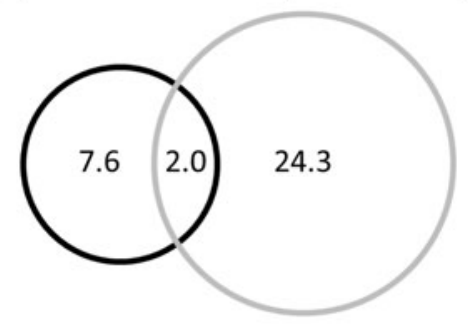

(e) Environment + Understory Biota $=22.2 \%$

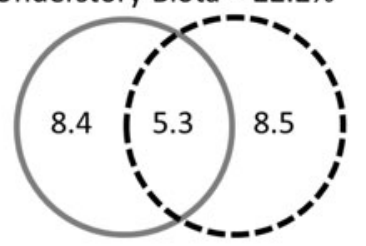

(c) Climate + Understory Biota $=19.0 \%$

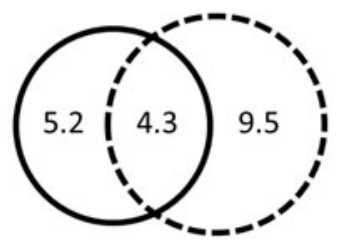

(f) Overstory + Understory Biota $=33.4 \%$

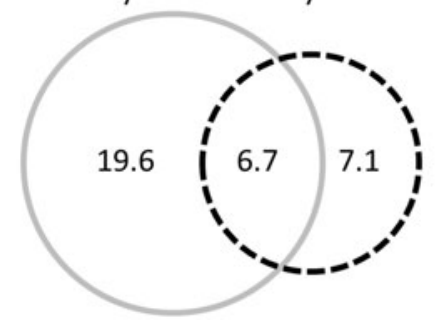

Fig. 3 Variation partitioning results for all pairs of drivers. Venn diagrams show explanatory relationships among all pairs of tree regeneration driver sets $(\mathbf{a}-\mathbf{f})$. Variation explained $(\%)$ is based on adj. $R^{2}$. All unique portions (non-overlapping outer section of each circle) explained a significant portion of regeneration layer variation $(P<0.005)$. The overlapping middle sections represent the 'shared' portion or variation

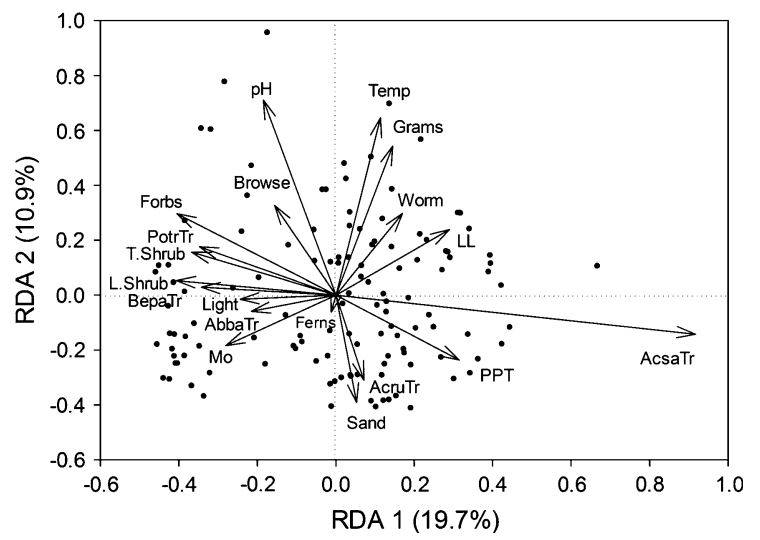

Fig. 4 Redundancy analysis (RDA) correlation biplot for the 19 significant explanatory variables in four driver sets (climate, understory environment, overstory composition, and understory biota) identified during variation partitioning. The response data are the Hellinger transformed stem densities of tree species in the regeneration layer. Explanatory variables are shown as vectors and sites as points. See Table 1 for explanations of acronyms

may increase the explanatory role of climate across the region. In any case, other variable sets, such as overstory composition, had greater explanatory roles explained by both drivers. Climate is represented by solid black circles, understory environment by dark gray, overstory by light gray, and understory biota by dashed black circles. The size of each circle section is proportional to the variation accounted for by that element. See text for specific variables within each driver set

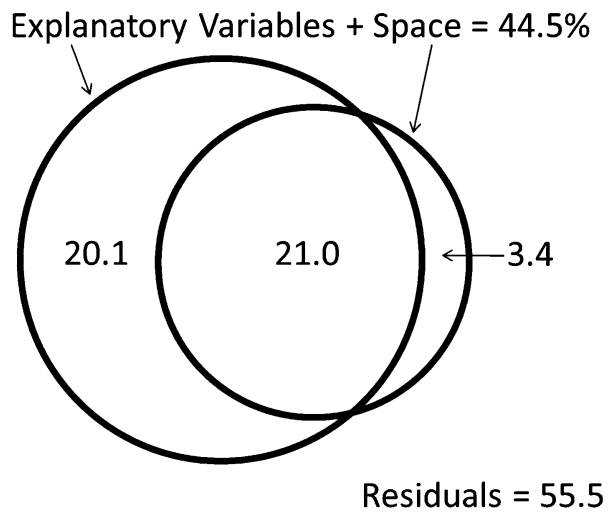

Fig. 5 Venn diagram depicting the partitioning of variation in the tree regeneration layer among explanatory variables (climate, understory environment, overstory composition, and understory biota) (left circle) and spatial variables (right circle). The explanatory drivers include 13 variables and the spatial set includes 15 principal coordinates of neighbor matrices (PCNM) eigenfunctions selected during stepwise selection procedures. Explained variation percentages are based on adj. $R^{2}$ values

than climate and indicate that the rate and direction of climate-mediated changes in forest composition will depend on the strengths of these factors (Clark et al. 2011). Furthermore, the relative importance of these 
other variables is likely to vary in the future due to direct and indirect relationships with a rapidly changing climate.

Spatially patterned and unexplained variation

Overall our model successfully accounted for most of the spatially patterned variation in regeneration across the landscape and the majority of unexplained variation was not spatially structured. The unexplained spatial patterning ( $3 \%$ ) may be associated with an unmeasured but spatially structured explanatory variable or indicate nonlinear relationships that were not accounted for by monomial predictors. Nearest neighbor distance among study sites was $10 \mathrm{~km}$ and the minimum distance was $1 \mathrm{~km}$, thus spatial patterning in regeneration is likely induced by spatially structured explanatory variables and not due to spatial autocorrelation (Legendre and Legendre 1998). The large majority of unexplained variation $(55.5 \%)$ did not have a spatial structure and was likely due to unmeasured locally varying factors and stochastic events. Unknown but potentially important local factors include disturbance (Turner et al. 2001) and land-use history (Foster et al. 2003), which can both have long-lasting effects on community composition. Since only one-quarter of the variation in tree regeneration had a detectable spatial structure (right-hand 'Space' circle in Fig. 5), local variables and events likely dominate tree regeneration trends across the study region. Additionally, this study was based on a single sampling period and thus variability in seed production, germination, recruitment, and mortality may have also contributed to unexplained variation (Beckage et al. 2005).

Overstory, environmental, and biotic variables and interrelationships with climate

Although much current research emphasis is placed on climate, our research shows that the relative strengths of other interrelated variables must be taken into account when attempting to project climate-mediated changes in forest composition. Three variables in particular, current overstory composition, soil $\mathrm{pH}$, and understory biota, appear most likely to interact with a changing climate and influence future forest composition.

The central role of the current overstory has strong implications on the rate of forest change. The high unique explanatory power of overstory composition was likely mainly due to direct influence on propagule availability. The ability of current advance regeneration to fill future gaps in the canopy will depend on the type and severity of future disturbances, which in the case of natural agents are themselves partly driven by climate. If the understory is left intact, for example after a wind storm that topples a few canopy trees, then advance regeneration is likely to fill these gaps and thus the current overstory will have great influence on future forest composition. This dynamic has two main implications. First, at the local scale temperate species already present in the overstory may be able to make substantial expansions through gap dynamics. Secondly and at a larger spatial scale, compositional shifts in the direction predicted by climate change may be slowed by the legacy effect of the current overstory. In boreal dominated areas, more severe disturbances such as intense fires which remove large portions of both the understory and overstory may be required to facilitate the rapid establishment of new species not present in the previous overstory neighborhood and that may be better adapted to the changed climate.

Given the current overstory composition and thus propagule availability, soil $\mathrm{pH}$ and related factors are likely to play a major role in determining which tree species (and where) are actually able to respond to a changing climate. For example, nutrient demanding temperate species will likely perform better under warmer temperatures at less acidic sites. It is important to note here that this response will be constrained by the covarying relationship between soil $\mathrm{pH}$ and annual precipitation. Precipitation increases and soil $\mathrm{pH}$ decreases from west to east across the region (Fig. 1b, $\mathrm{g}$ ), thus species otherwise inhibited by strongly acidic conditions may be best able to respond to future warming at the western end of the temperate-boreal transition zone, assuming adequate precipitation levels.

While soil $\mathrm{pH}$ was a strong understory environment explanatory variable, soil sand fraction showed low explanatory power and clay was surprisingly not a significant factor. Sand was negatively related to annual precipitation, i.e., temperate-boreal forests were more confined to finer textured soils at drier sites_-itself an interesting finding — but were found on a wider variety of textures at wetter sites, analogous to the results of Henne et al. (2007). Relatively wet conditions over the past three decades (Karl et al. 2009) may have limited the significance of soil texture 
as a regeneration driver. If the future climate becomes more droughty, mesic mixed stands currently on coarse textured soils may shift composition more dramatically towards drought tolerant species than stands on finer textured soils with higher moisture holding capacity.

Understory biota are likely to play a dynamic role in influencing tree regeneration patterns under a global change scenario. The strengths of relationships between tree regeneration and understory biota will vary depending on how understory biota respond to a changing climate. For example, both forb cover and shrub abundance showed a negative relationship with precipitation while graminoid cover increased with temperature across the region. Thus tree species attempting to track climate change and shift their ranges will have to compete with these also climatesensitive vegetation groups (Royo and Carson 2006). The strong relationship between climate and understory biota also implies that overall understory community composition may be shifting with climate. Because species richness in these forests is greatest in the understory, these shifts will affect overall biodiversity and ecosystem functioning (Gilliam 2007).

\section{Conclusion}

The tree regeneration layer in mixed stands responds to multiple interrelated variables. Continued shifts in climate and especially warming and drying during the summer months are likely to accelerate changes in tree regeneration composition, although this will largely depend on propagule availability, soil nutrient status, and interactions with other understory biota. Moreover, since these other variables also have interrelationships with climate, the direction and rate of forest change may hinge on how the importance of these factors shifts with climate and, for the biotic variables, on the rate and magnitude of their own responses to climate change.

Acknowledgments Financial support was provided by the U.S. Environmental Protection Agency's STAR Fellowship program; Hubachek Wilderness Research Foundation; University of Minnesota Wood-Rill Fellowship; DaytonWilkie Natural History Fund of the Bell Museum of Natural History; and University of Minnesota Carolyn Crosby Fellowship. We thank K. Riemersma, B. Wageman, and L. Miller for assistance with field work. C. Kern, T. Serres, A. D'Amato, K. Kipfmueller, and two anonymous reviewers provided valuable comments on the manuscript.
Open Access This article is distributed under the terms of the Creative Commons Attribution License which permits any use, distribution, and reproduction in any medium, provided the original author(s) and the source are credited.

\section{References}

Arii K, Lechowicz MJ (2002) The influence of overstory trees and abiotic factors on the sapling community in an oldgrowth Fagus-Acer forest. Ecoscience 9:386-396

Barnes BV, Zak DR, Denton SR, Spurr SH (1998) Forest ecology, 4th edn. John Wiley \& Sons, Inc., New York

Beckage B, Lavine M, Clark JS (2005) Survival of tree seedlings across space and time: estimates from long-term count data. J Ecol 93:1177-1184

Blanchet FG, Legendre P, Borcard D (2008) Forward selection of explanatory variables. Ecology 89:2623-2632

Borcard D, Legendre P (2002) All-scale spatial analysis of ecological data by means of principal coordinates of neighbour matrices. Ecol Model 153:51-68

Borcard D, Legendre P, Drapeau P (1992) Partialling out the spatial component of ecological variation. Ecology 73:1045-1055

Buell MF, Martin WE (1961) Competition between maplebasswood and fir-spruce communities in Itasca Park, Minnesota. Ecology 42:428-429

Canham CD, Berkowitz AR, Kelly VR, Lovett GM, Ollinger SV, Schnurr J (1996) Biomass allocation and multiple resource limitation in tree seedlings. Can $\mathrm{J}$ For Res 26:1521-1530

Clark JS, Bell DM, Hersh MH, Nichols L (2011) Climate change vulnerability of forest biodiversity: climate and competition tracking of demographic rates. Global Change Biol 17:1834-1849

Côté SD, Rooney TP, Tremblay JP, Dussault C, Waller DM (2004) Ecological impacts of deer overabundance. Annu Rev Ecol Evol Syst 35:113-147

Daly C, Halbleib M, Smith JI, Gibson WP, Doggett MK, Taylor GH, Curtis J, Pasteris PP (2008) Physiographically sensitive mapping of climatological temperature and precipitation across the conterminous United States. Int J Climatol 28:2031-2064

Diochon A, Rigg LS, Goldblum D, Polans N (2003) Regeneration dynamics and genetic variability of sugar maple (Acer saccharum [marsh]) seedlings at the species' northern growth limit, Lake Superior Provincial Park, Canada. Phys Geogr 24:399-413

Eisenhauer N, Partsch S, Parkinson D, Scheu S (2007) Invasion of a deciduous forest by earthworms: changes in soil chemistry, microflora, microarthropods and vegetation. Soil Biol Biochem 39:1099-1110

Finzi AC, Canham CD, Van Breemen N (1998) Canopy tree-soil interactions within temperate forests: species effects on $\mathrm{pH}$ and cations. Ecol Appl 8:447-454

Fisichelli NA (2012) Tree regeneration dynamics and drivers across the temperate-boreal transition zone. Dissertation, University of Minnesota

Fisichelli NA, Frelich LE, Reich PB (2012) Sapling growth responses to warmer temperatures 'cooled' by browse pressure. Global Change Biol 18:3455-3463 
Forcier LK (1975) Reproductive strategies and the co-occurrence of climax tree species. Science 189:808-810

Foster D, Swanson F, Aber J, Burke I, Brokaw N, Tilman D, Knapp A (2003) The importance of land-use legacies to ecology and conservation. Bioscience 53:77-88

Frelich LE, Reich PB (1995) Spatial patterns and succession in a Minnesota southern-boreal forest. Ecol Monogr 65:325-346

Frelich LE, Reich PB (2009) Wilderness conservation in an era of global warming and invasive species: a case study from Minnesota's boundary waters canoe area wilderness. Nat Areas J 29:385-393

Frelich LE, Reich PB (2010) Will environmental changes reinforce the impact of global warming on the prairie-forest border of central North America? Front Ecol Environ 8:371-378

Frelich LE, Calcote RR, Davis MB, Pastor J (1993) Patch formation and maintenance in an old-growth hemlock-hardwood forest. Ecology 74:513-527

Frelich LE, Hale CM, Scheu S et al (2006) Earthworm invasion into previously earthworm-free temperate and boreal forests. Biol Invasions 8:1235-1245

Gilliam FS (2007) The ecological significance of the herbaceous layer in temperate forest ecosystems. Bioscience 57:845-858

Goldblum D, Rigg LS (2010) The deciduous forest-boreal forest ecotone. Geogr Compass 4:701-717

Grubb P (1977) The maintenance of species-richness in plant communities: the importance of the regeneration niche. Biol Rev 52:107-145

Henne PD, Hu FS, Cleland DT (2007) Lake-effect snow as the dominant control of mesic-forest distribution in Michigan, USA. J Ecol 95:517-529

Iverson LR, Prasad AM (1998) Predicting abundance of 80 tree species following climate change in the eastern United States. Ecol Monogr 68:465-485

Karl TR, Melillo JM, Peterson TC (2009) Global climate change impacts in the United States. Cambridge University Press, New York

Kneeshaw DD, Bergeron Y (1996) Ecological factors affecting the abundance of advance regeneration in Quebec's southwestern boreal forest. Can J For Res 26:888-898

Kneeshaw DD, Prevost M (2007) Natural canopy gap disturbances and their role in maintaining mixed-species forests of central Quebec, Canada. Can J For Res 37:1534-1544

Legendre P, Gallagher ED (2001) Ecologically meaningful transformations for ordination of species data. Oecologia 129:271-280

Legendre P, Legendre L (1998) Numerical ecology, 2nd English edition. Elsevier Science, Amsterdam

McEwan RW, Dyer JM, Pederson N (2011) Multiple interacting ecosystem drivers: toward an encompassing hypothesis of oak forest dynamics across eastern North America. Ecography 34:244-256

Millar CI, Stephenson NL, Stephens SL (2007) Climate change and forests of the future: managing in the face of uncertainty. Ecol Appl 17:2145-2151

MN DNR (2003) Field guide to the native plant communities of Minnesota: the Laurentian mixed forest province. Ecological land classification program, Minnesota County biological survey, and natural heritage and nongame research program. Minnesota Department of Natural Resources, St. Paul

Økland RH, Eilertsen O (1994) Canonical correspondence analysis with variation partitioning: some comments and an application. J Veg Sci 5:117-126

Oksanen J, Blanchet FG, Kindt R et al (2011) Vegan: community ecology package. $\mathrm{R}$ package version 1.17-6. http://cran.r-project.org. Accessed 1 Feb 2011

Oliver CD (1980) Forest development in North America following major disturbances. For Ecol Manag 3:153-168

Pastor J, Mladenoff DJ (1992) The southern boreal-northern hardwood forest border. In: Shugart HH, Leemans R, Bonan GB (eds) A systems analysis of the global boreal forest. Cambridge University Press, Cambridge, pp 216-240

Peres-Neto PR, Legendre P, Dray S et al (2006) Variation partitioning of species data matrices: estimation and comparison of fractions. Ecology 87:2614-2625

Prentice IC, Sykes MT, Cramer W (1991) The possible dynamic response of northern forests to global warming. Global Ecol Biogeogr Lett 1:129-135

R Development Core Team (2008) R: A language and environment for statistical computing. R Foundation for Statistical Computing, Vienna. http://www.R-project.org. Accessed 1 Feb 2011

Royo AA, Carson WP (2006) On the formation of dense understory layers in forests worldwide: consequences and implications for forest dynamics, biodiversity, and succession. Can J For Res 36:1345-1362

Scheller RM, Mladenoff DJ (2005) A spatially interactive simulation of climate change, harvesting, wind, and tree species migration and projected changes to forest composition and biomass in northern Wisconsin, USA. Global Change Biol 11:307-321

Schulte LA, Mladenoff DJ (2005) Severe wind and fire regimes in northern forests: historical variability at the regional scale. Ecology 86:431-445

Turner MG, Gardner RH, O’Neill RV (2001) Landscape ecology in theory and practice: pattern and process. Springer, New York

Walters MB, Reich PB (1996) Are shade tolerance, survival, and growth linked? Low light and nitrogen effects on hardwood seedlings. Ecology 77:841-853 